\title{
Combined endobronchial and oesophageal endosonography for the diagnosis and staging of lung cancer
}

European Society of Gastrointestinal Endoscopy (ESGE) Guideline, in cooperation with the European Respiratory Society (ERS) and the European Society of Thoracic Surgeons (ESTS)

Peter Vilmann ${ }^{1}$, Paul Frost Clementsen ${ }^{2,3}$, Sara Colella ${ }^{2}$, Mette Siemsen ${ }^{4}$, Paul De Leyn ${ }^{5}$, Jean-Marc Dumonceau ${ }^{6}$, Felix J. Herth ${ }^{7}$, Alberto Larghi, Enrique Vazquez-Sequeiros ${ }^{9}$, Cesare Hassan $^{8}$, Laurence Crombag $^{10}$, Daniël A. Korevaar ${ }^{11}$, Lars Konge ${ }^{3}$ and Jouke T. Annema ${ }^{10}$

Affiliations: ${ }^{1}$ Dept of Surgical Gastroenterology, Endoscopy Unit, Copenhagen University Hospital Herlev, Copenhagen, Denmark. ${ }^{2}$ Dept of Pulmonary Medicine, Gentofte University Hospital, Hellerup, Denmark. ${ }^{3}$ Centre for Clinical Education, University of Copenhagen and the Capital Region of Denmark, Copenhagen, Denmark. ${ }^{4}$ Dept of Thoracic Surgery, Rigshospitalet, Copenhagen Hospital Union, Copenhagen, Denmark. ${ }^{5}$ Dept of Thoracic Surgery, University Hospitals Leuven, Belgium. ${ }^{6}$ Gedyt Endoscopy Center, Buenos Aires, Argentina. ${ }^{7}$ Dept of Pneumology and Critical Care Medicine, Thoraxklinik, University of Heidelberg, Heidelberg, Germany. ${ }^{8}$ Digestive Endoscopy Unit, Catholic University, Rome, Italy. ${ }^{9}$ Dept of Gastroenterology, University Hospital Ramón y Cajal, Universidad de Alcala, Madrid, Spain. ${ }^{10}$ Dept of Respiratory Medicine, Academic Medical Center, University of Amsterdam, Amsterdam, The Netherlands. ${ }^{11}$ Dept of Clinical Epidemiology, Biostatistics and Bioinformatics, Academic Medical Center, University of Amsterdam, Amsterdam, The Netherlands.

Correspondence: Peter Vilmann, GastroUnit, Dept of Surgery, Copenhagen University Hospital Herlev Copenhagen, Denmark. E-mail: Peter.Vilmannaregionh.dk

@ERSpublications

New guidelines for combined endobronchial and oesophageal mediastinal nodal staging of lung cancer http://ow.ly/MwM4H

This is an official guideline of the European Society of Gastrointestinal Endoscopy (ESGE), produced in cooperation with the European Respiratory Society (ERS) and the European Society of Thoracic Surgeons (ESTS). It addresses the benefit and burden associated with combined endobronchial and oesophageal mediastinal nodal staging of lung cancer. The Scottish Intercollegiate Guidelines Network (SIGN) approach was adopted to define the strength of recommendations and the quality of evidence.

This article has supplementary material available from erj.ersjournals.com

Received: April 232015 | Accepted: April 272015 | First published online: June 012015

Conflict of interest: Disclosures can be found alongside the online version of this article at erj.ersjournals.com

The article has been co-published with permission in the European Journal of Cardio-Thoracic Surgery, European Respiratory Journal and Endoscopy Journal. All rights reserved. OERS 2015. 


\section{Recommendations}

1. For mediastinal nodal staging in patients with suspected or proven non-small cell lung cancer (NSCLC) with abnormal mediastinal and/or hilar nodes at computed tomography (CT) and/or positron emission tomography (PET), endosonography is recommended over surgical staging as the initial procedure (recommendation grade $\mathrm{A}$ ).

The combination of endobronchial ultrasound with real-time guided transbronchial needle aspiration (EBUS-TBNA) and endoscopic (oesophageal) ultrasound with fine needle aspiration, with use of a gastrointestinal (EUS-FNA) or EBUS (EUS-B-FNA) scope, is preferred over either test alone (recommendation grade C). If the combination of EBUS and EUS-(B) is not available, we suggest that EBUS alone is acceptable (recommendation grade C).

Subsequent surgical staging is recommended, when endosonography does not show malignant nodal involvement (recommendation grade B).

2. For mediastinal nodal staging in patients with suspected or proven non-small cell peripheral lung cancer without mediastinal involvement at CT or CT-PET, we suggest that EBUS-TBNA and/or EUS-(B)-FNA should be performed before therapy, provided that one or more of the following conditions is present: 1 ) enlarged or fluorodeoxyglucose (FDG)-PET-avid ipsilateral hilar nodes; 2) primary tumour without FDG uptake; 3 ) tumour size $\geqslant 3 \mathrm{~cm}$ (fig. $3 \mathrm{a}-\mathrm{c}$ ) (recommendation grade C).

If endosonography does not show malignant nodal involvement, we suggest that mediastinoscopy is considered, especially in suspected $\mathrm{N} 1$ disease (recommendation grade $\mathrm{C}$ ).

If PET is not available and CT does not reveal enlarged hilar or mediastinal lymph nodes, we suggest performance of EBUS-TBNA and/or EUS-(B)-FNA and/or surgical staging (recommendation grade C).

3. In patients with suspected or proven $<3 \mathrm{~cm}$ peripheral NSCLC with normal mediastinal and hilar nodes at CT and/or PET, we suggest initiation of therapy without further mediastinal staging (recommendation grade C).

4. For mediastinal staging in patients with centrally located suspected or proven NSCLC without mediastinal or hilar involvement at CT and/or CT-PET, we suggest performance of EBUS-TBNA, with or without EUS-(B)-FNA, in preference to surgical staging (fig. 4) (recommendation grade D).

If endosonography does not show malignant nodal involvement, mediastinoscopy may be considered (recommendation grade D).

5. For mediastinal nodal restaging following neoadjuvant therapy, EBUS-TBNA and/or EUS-(B)-FNA is suggested for detection of persistent nodal disease, but, if this is negative, subsequent surgical staging is indicated (recommendation grade $\mathrm{C}$ ).

6. A complete assessment of mediastinal and hilar nodal stations, and sampling of at least three different mediastinal nodal stations ( $4 \mathrm{R}, 4 \mathrm{~L}, 7$ ) (figs 1 and 5) is suggested in patients with NSCLC and an abnormal mediastinum by CT or CT-PET (recommendation grade D).

7. For diagnostic purposes, in patients with a centrally located lung tumour that is not visible at conventional bronchoscopy, endosonography is suggested, provided the tumour is located immediately adjacent to the larger airways (EBUS) or oesophagus (EUS-(B)) (recommendation grade D).

8. In patients with a left adrenal gland suspected for distant metastasis we suggest performance of endoscopic ultrasound fine needle aspiration (EUS-FNA) (recommendation grade C), while the use of EUS-B with a transgastric approach is at present experimental (recommendation grade D).

9. For optimal endosonographic staging of lung cancer, we suggest that individual endoscopists should be trained in both EBUS and EUS-B in order to perform complete endoscopic staging in one session (recommendation grade D).

10. We suggest that new trainees in endosonography should follow a structured training curriculum consisting of simulation-based training followed by supervised practice on patients (recommendation grade D).

11. We suggest that competency in EBUS-TBNA and EUS-(B)-FNA for staging lung cancer be assessed using available validated assessment tools (recommendation grade D). 


\section{Introduction}

Lung cancer is the most common cause of cancer-related mortality worldwide, causing approximately 1.2 million deaths every year [1]. In Europe, 410000 new cases of lung cancer and 353000 related deaths have been estimated to have occurred in 2012. Most cases concern non-small cell lung cancer (NSCLC) [1]. Accurate staging is mandatory for planning optimal treatment [2]. Surgery or radiotherapy with curative intent is advised in the case of localised disease. Spread to ipsilateral (N2) or contralateral (N3) mediastinal lymph nodes marginalises the role of surgery as first-line treatment. For disseminated NSCLC and small cell lung cancer (SCLC), chemotherapy and/or radiotherapy is recommended [3].

Imaging by computed tomography (CT) and/or positron emission tomography (PET) should be obtained to characterise the primary lung lesion and the mediastinum, and to search for metastases. Although the detection of enlarged (at CT, short axis $>10 \mathrm{~mm}$ ) or fluorodeoxyglucose (FDG)-avid mediastinal lymph nodes at PET increases the probability of malignant involvement $[4,5]$, nevertheless the accuracy of radiological imaging in mediastinal staging is suboptimal [6-8]. Therefore, additional mediastinal tissue staging is frequently required to confirm or exclude metastatic mediastinal nodal involvement. This applies not only in patients who present with an abnormal mediastinum [9-11], but also in those with a normal mediastinum but increased risk of mediastinal involvement because of hilar abnormalities or a centrally located lung tumour [12].

Mediastinoscopy has been demonstrated to have an adequate accuracy for mediastinal nodal staging [13], but is also associated with morbidity and significant costs [13]. Endoscopic ultrasound-guided fine needle aspiration (EUS-FNA) and endobronchial ultrasound with real-time guided transbronchial needle aspiration (EBUS-TBNA) represent valuable alternatives to surgical staging (box 1) [14-18]. Both techniques are minimally invasive, safe, well-tolerated, and rarely require general anaesthesia [14, 19, 20]. Recently, endosonography has been recommended in guidelines as the initial test of choice over surgical staging [21, 22], because it improves nodal tissue staging, reduces the number of futile thoracotomies [18], and is cost-effective $[23,24]$. The integration of the two techniques in a single "combined" endoscopic approach to staging of the mediastinum has been shown to further increase the accuracy as compared with either technique alone [25].

The aim of this guideline, from the European Society of Gastrointestinal Endoscopy (ESGE) in cooperation with the European Respiratory Society (ERS) and the European Society for Thoracic Surgery (ESTS), is to address the benefit and burden associated with mediastinal nodal staging of lung cancer by combined endobronchial ultrasound (EBUS) and endoscopic oesophageal ultrasound (EUS-(B); that is, with use of either the gastrointestinal or the EBUS scope). Additionally the use of EBUS/EUS for the analysis of the primary lung tumour and the left adrenal gland will be addressed, as will training issues.

\section{DEFINITIONS AND ABBREVIATIONS}

\section{CT-PET \\ EBUS-TBNA}

EUS

EUS-B

EUS-(B)

FNA

TBNA

TEMLA

Combined endosonography Complete mediastinal nodal staging

Targeted mediastinal nodal staging

Centrally located lung tumour Peripherally located lung cancer Lymph node(s) suspicious for malignancy (abnormal mediastinum)
Integrated computed and positron emission tomography

Endobronchial ultrasound with real-time guided transbronchial needle aspiration

Endoscopic (oesophageal) ultrasound using the gastrointestinal scope

Endoscopic loesophageal) ultrasound using the EBUS scope

Endoscopic (oesophageal) ultrasound using either the gastrointestinal or EBUS scope

Fine needle aspiration

Transbronchial needle aspiration

Transcervical extended bilateral mediastinal lymph adenectomy

EBUS-TBNA and EUS-(B)-FNA combined

All nodes evaluated lin contrast to only analysis of suspected nodes based on CT and/or PET imaging)

Evaluation of the nodels) that is (are) suspicious on CT and/ or PET

Lung tumour located within the inner third of the chest

Lung tumour located within the outer two thirds of the chest

Node with a short axis $(>10 \mathrm{~mm})$ and/or that is FDG-PET-avid 
BOX 1 Mediastinal nodal staging related to diagnostic reach of endobronchial ultrasound (EBUS) and endoscopic (oesophageal) ultrasound (EUS) (fig. 1)

No single mediastinal tissue sampling method can reach all mediastinal nodal stations.

The diagnostic yield of EBUS-transbronchial needle aspiration (EBUS-TBNA) is related to those mediastinal and hilar nodes that are located immediately adjacent to the trachea and larger airways. These comprise stations $2 \mathrm{~L}, 2 \mathrm{R}, 4 \mathrm{~L}, 4 \mathrm{R}$, and station 7 . EBUS, uniquely, can sample tissue from the hilar nodes (station 10) and from the intrapulmonary nodes (stations 11-12).

EUS with real-time guided fine needle aspiration using the EBUS scope (EUS-B-FNA) can reach the following locations that are relevant to lung cancer diagnosis and staging [14-16]: lung tumours close to the oesophagus; mediastinal lymph nodes in stations 2L, 4L (high and lower left paratracheal nodes); station 7 (subcarinal node); stations 8 and 9 (nodes located in the lower mediastinum); and structures below the diaphragm, i.e. retroperitoneal lymph nodes close to the aorta and the celiac trunk, and tumours in the left liver lobe and the left adrenal gland [17]. Stations $2 R$ and $4 R$ (paratracheally to the right) are difficult to reach because the trachea lies between the transducer and the lymph node, limiting visualisation of this area. In selected cases of large lymph nodes $(>2 \mathrm{~cm})$, however, visualisation and subsequent sampling is possible.

Stations 5 and 6 can be well visualised by EUS but can rarely be sampled without traversing the pulmonary artery/aorta. These stations are predominantly affected by left upper lobe tumours. Surgical staging by video-assisted thoracic surgery is the method of choice for nodes in stations 5 and 6 .

The hilar regions (lung tumours and lymph nodes in stations 10,11, and 12 (right/left)) cannot be reached by EUS-FNA, but they can be sampled using EBUS-TBNA. Combining these two techniques allows sampling of virtually all mediastinal nodal stations (fig. 1) [18]. The frequently affected nodes in locations $4 \mathrm{~L}$ and 7 are accessible by both techniques.

FIGURE 1 The complementary nature of endobronchial ultrasound (EBUS) and endoscopic (oesophageal) ultrasound (EUS) for nodal staging.
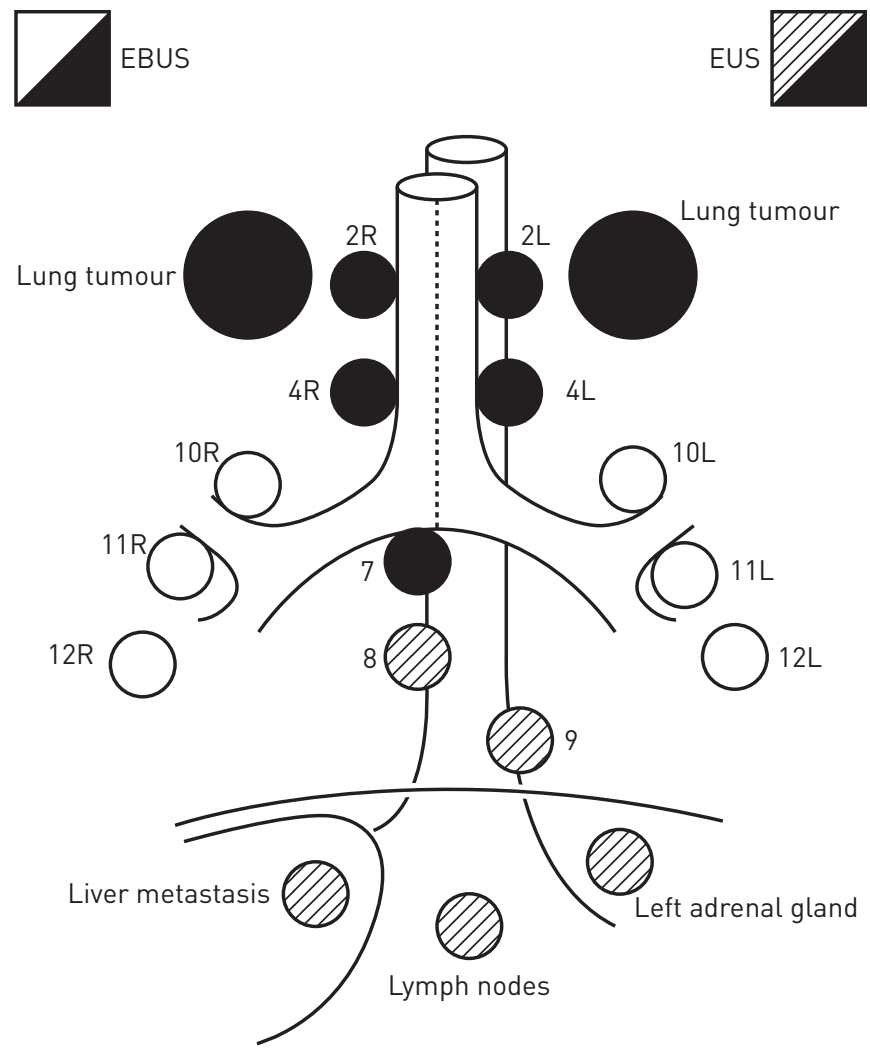

\section{Methods}

This guideline was commissioned by the ESGE and produced in cooperation with the ERS and ESTS. The guideline development process included meetings, telephone conferences, and internet-based discussions, between October 2012 and December 2014, among members of the guideline committee who had been selected by the involved societies.

Subgroups were formed, each in charge of a series of clearly defined key questions (online appendix e1). These working group members identified appropriate search terms and parameters to direct the literature search. A thorough search of MEDLINE (accessed through PubMed), Web of Science, Cochrane Database 
of Systematic Reviews, and Cochrane Central Register of Controlled Trials was performed. Specific search strategies, including search terms, parameters, and databases searched, are documented for each question in online appendix e2. English language literature concerning the combination of EBUS-TBNA and EUS-(B)-FNA in the diagnosis and in the staging of lung cancer was selected. Literature on the combination of EBUS and EUS as well as on EUS or EBUS alone was selected for review. Initially, studies were selected from a period limited to 1990 to October 2013. However, because of delay in the preparation of the manuscript it was decided to additionally include a few important studies published after the search period. Working group members reviewed all abstracts yielded from the literature search and identified the full-text articles they would review in order to address the clinical questions. Members identified the best research evidence available to answer the key questions. The guideline considers only the linear (not radial) probe technique.

\section{Assessment of level of evidence and grade of recommendations}

All selected papers were reviewed independently by two investigators. Disagreements were solved through discussion within the review team. Evidence levels and recommendation grades used in this guideline were slightly modified from those recommended by the Scottish Intercollegiate Guidelines Network (SIGN) [26] and are described in table 1. The SIGN approach classifies recommendations according to the quality of evidence, taking also into consideration whether the studies were directly applicable to the study population. Evidence tables are detailed in online appendix e3.

Caution should be used in developing guidelines and recommendations for diagnostic tests and strategies. Usually, when clinicians consider diagnostic tests, they focus on accuracy (sensitivity and specificity); that is, how well the test classifies patients correctly as having or not having a target disease, as determined by a clinical reference standard. The underlying assumption is, however, that obtaining a better idea of whether a target condition is present or absent will result in improved patient-important outcomes. The best way to assess any diagnostic strategy is a randomised controlled trial in which investigators randomise patients to experimental or control diagnostic approaches and measure mortality, morbidity, symptoms, and/or quality of life. When studies were available that compared the impact of alternative diagnostic

TABLE 1 Definitions of categories for evidence levels and recommendation grades used in this guideline

\section{Evidence level}

$1++\quad$ High quality meta-analyses, systematic reviews of randomised controlled trials

or randomised controlled trials with a very low risk of bias

$1+\quad$ Well conducted meta-analyses, systematic reviews of randomised controlled trials

or randomised controlled trials with a low risk of bias

1- $\quad$ Meta-analyses, systematic reviews or randomised controlled trials with a high risk of bias

2++ High quality systematic reviews of case-control or cohort studies; high quality case-control studies or cohort studies with a very low risk of confounding, bias, or chance and a high probability that the relationship is causal

2+ Well conducted case-control or cohort studies with a low risk of confounding, bias, or chance and a moderate probability that the relationship is causal

2- Case-control or cohort studies with a high risk of confounding, bias, or chance and a significant risk that the relationship is not causal

$3 \quad$ Nonanalytic studies, e.g. case reports, case series

$4 \quad$ Expert opinion

\section{Recommendation grade}

At least one meta-analysis, systematic review, or randomised controlled trial rated as $1++$ and directly applicable to the target population

or a systematic review of randomised controlled trials

or a body of evidence consisting principally of studies rated as 1+ directly applicable to the target population and demonstrating overall consistency of results

B A body of evidence including studies rated as 2++ directly applicable to the target population and demonstrating overall consistency of results

or extrapolated evidence from studies rated as $1++$ or $1+$

C A body of evidence including studies rated as 1- or 2+ directly applicable to the target population and demonstrating overall consistency of results

or extrapolated evidence from studies rated as $2++$

D Evidence level 2-, 3 or 4

or extrapolated evidence from studies rated as $2+$ 
strategies on patient-important outcomes they were taken into account. Otherwise, test accuracy was used as a surrogate for patient-important outcome.

After a final meeting in June 2014, all authors agreed on the final revised manuscript, which was submitted to the official journals of the societies. This guideline was issued in 2015 and will be considered for review in 2019, or sooner if new and crucial evidence becomes available. Any updates of the guideline in the interim will be noted on the websites of the ESGE (www.esge.com/esge-guidelines.html), ERS (www. ers-education.org/guidelines.aspx) and ESTS (www.ests.org/guidelines_and_evidence/ests_guidelines.aspx).

\section{Recommendation 1}

For mediastinal nodal staging in patients with suspected or proven NSCLC with abnormal mediastinal and/or hilar nodes at CT and/or PET, endosonography is recommended over surgical staging as the initial procedure (recommendation grade $\mathbf{A}$ ).

The combination of endobronchial ultrasound with real-time guided transbronchial needle aspiration (EBUS-TBNA) and endoscopic (oesophageal) ultrasound with fine needle aspiration, with use of a gastrointestinal (EUS-FNA) or EBUS (EUS-B-FNA) scope is preferred over either test alone (recommendation grade C). If the combination of EBUS and EUS-(B) is not available, we suggest that EBUS alone is acceptable (recommendation grade C).

Subsequent surgical staging is recommended, when endosonography does not show malignant nodal involvement (recommendation grade B).

\section{Background}

In patients with (suspected) potentially curable NSCLC, pathologic confirmation of mediastinal lymph nodes is indicated in patients with hilar and/or mediastinal lymph nodes that are enlarged and/or FDG-avid at positron emission tomography (PET) [27]. This is mandatory because the probability of having lymph node metastases, based on an abnormal mediastinum on CT or PET imaging, ranges from $50 \%$ to $80 \%$. The false-positive rate is especially considerable when tumours are accompanied by inflammation [28].

\section{Review of the studies}

\section{Endosonography versus surgical staging}

The ASTER study (Assessment of Surgical sTaging versus Endobronchial and endoscopic ultrasound in lung cancer: a randomized controlled trial) by ANNEMA et al. [18] compared immediate surgical mediastinal staging versus combined endosonography staging (endobronchial ultrasound (EBUS) and endoscopic oesophageal ultrasound (EUS) combined) followed by surgical staging if no mediastinal nodal metastases were detected. In detail, 241 patients with enlarged or FDG-avid mediastinal lymph nodes, enlarged or FDG-avid hilar lymph nodes, or a central lung lesion were randomised. The reference standard was surgical pathological staging including mediastinal nodal dissection. The sensitivity for mediastinal lymph node metastasis was $79 \%$ for surgical staging versus $94 \%$ for endosonography followed by surgical staging $(\mathrm{p}=0.04)$, with corresponding negative predictive values of $86 \%$ and $93 \%(\mathrm{p}=0.26)$, respectively. The sensitivity of the combination of EUS and EBUS alone, without subsequent surgical staging, was $85 \%$; this was not significantly different from immediate surgical staging. Among patients with (suspected) NSCLC, a staging strategy combining endosonography and surgical staging versus immediate surgical staging reduced the percentage of unnecessary thoracotomies from $18 \%$ to $7 \%$ $(\mathrm{p}=0.02)[18]$.

In the ASTER study [18], following a negative endosonography, 65 patients underwent mediastinoscopy which detected six additional cases of $\mathrm{N} 2 / \mathrm{N} 3$ disease. In the subgroup of patients with an abnormal mediastinum shown by radiological imaging, after a negative endosonography the post-test probability for lymph node metastasis was $20 \%$ (95\% CI 12\%-32\%), and adding a confirmatory mediastinoscopy in these patients with negative endosonography decreased the post-test probability for missed nodal metastases to $5 \%$ (95\% CI 2\%-20\%) [27]. Therefore, additional surgical staging, especially in this specific subset of patients, is indicated. If negative endosonography results are not followed by confirmatory surgical staging, careful follow-up is mandatory.

\section{EBUS-TBNA or EUS with fine needle aspiration (FNA) alone}

The accuracy of EBUS-TBNA and EUS-FNA separately for assessing mediastinal lymph node metastases has been described in several studies. In a meta-analysis by Gu et al. [29], involving 11 studies and 1299 patients, the pooled sensitivity of EBUS-TBNA in mediastinal staging for lung cancer was 93\% (95\% CI 91\%-94\%). The reference standard was histopathology in five studies, and histopathology or clinical follow-up in six. In the subgroup of patients with an abnormal mediastinum on the basis of CT or PET, 
pooled sensitivity was $94 \%$ (95\% CI 93\%-96\%), which was significantly higher than for the subgroup of patients who were included regardless of CT or PET abnormalities (76\%, 95\% CI 65\%-85\%).

Concerning EUS-FNA, a meta-analysis by MiCAMES et al. [30] (18 studies, 1201 patients) reported a pooled sensitivity of $83 \%$ (95\% CI $78 \%-87 \%)$. The reference standard was histopathology in 10 studies, and histopathology or clinical follow-up in eight. The sensitivity was $90 \%$ (95\% CI $84 \%-94 \%$ ) in the subgroup of patients with abnormal mediastinal lymph nodes at radiological imaging, and 58\% (95\% CI 39\%-75\%) among patients without abnormal mediastinal lymph nodes. There was risk of bias in many of the studies included in these meta-analyses. This may have led to overestimations of the sensitivity of the tests.

EBUS-TBNA and EUS-(B)-FNA combination versus either technique alone

To date, no randomised controlled trials have been performed comparing the EBUS plus EUS-(B) combination versus either EBUS-TBNA or EUS-(B)-FNA alone.

\section{EBUS-TBNA and EUS-(B)-FNA combination studies}

We found 11 studies that assessed the accuracy of systematically performing both EBUS and EUS for mediastinal staging in (suspected) lung cancer patients (table 2) [18, 31-40]. In the prospective comparative study by WALLACE et al. [32], TBNA, EBUS-TBNA and EUS-FNA for mediastinal staging of lung cancer were performed in 138 patients against a reference standard of surgery or clinical follow-up. The overall sensitivity of the combination of EBUS-TBNA and EUS-FNA was 93\%. This was significantly higher than the sensitivities of EBUS-TBNA (69\%), EUS-FNA (69\%), and conventional TBNA (36\%) alone. VILMANN et al. [31] found that the accuracy of EUS-FNA and EBUS-TBNA in combination for the diagnosis of mediastinal cancer was $100 \%$ in 28 patients, against a reference standard of surgery or clinical follow-up.

The diagnostic value of the combined endosonography approach has recently been compared with that of CT-PET for mediastinal nodal staging of lung cancer [36]. Overall, 120 consecutive patients with suspected resectable lung cancer on CT findings (with and without enlarged mediastinal lymph nodes) underwent CT-PET and combined EUS-FNA plus EBUS-TBNA. A final pathological $\mathrm{N}$ stage was established in 110 patients. The accuracy of the combination of EUS-FNA plus EBUS-TBNA was significantly higher than that of CT-PET (90.0\% versus $73.6 \%)$.

HeRTh et al. [33] analysed 139 patients who underwent combined EBUS and EUS-B endosonographic staging. The reference standard was surgical confirmation or clinical follow-up. Sensitivity was $89 \%$ for EUS-FNA and $92 \%$ for EBUS-TBNA. The combined approach had a sensitivity of $96 \%$ and a negative predictive value of $96 \%$.

In a recent randomised controlled trial [37], 160 patients were randomised to either EBUS-TBNA followed by EUS-B-FNA (group A) or to receive EUS-B-FNA followed by EBUS-TBNA (group B). In both arms, the second procedure was performed on mediastinal nodes inaccessible or difficult to access by the first procedure. No significant differences in final accuracy emerged between groups A and B. However, while in group A, adding EUS-FNA to EBUS-TBNA did not significantly increase the accuracy or sensitivity, in group B, adding EBUS-TBNA to EUS-FNA did significantly increase the accuracy and sensitivity.

HwANGBo et al. [34] evaluated the role of EUS-B-FNA for mediastinal lymph nodes that were inaccessible or difficult to access by EBUS-TBNA in 143 patients, with a reference standard of surgical confirmation. The sensitivity, negative predictive value and diagnostic accuracy of EBUS-TBNA alone for the detection of mediastinal metastasis were $84.4 \%, 93.3 \%$ and $95.1 \%$, respectively. The corresponding values for the combination of EBUS-TBNA plus EUS-B-FNA increased to $91.1 \%, 96.1 \%$ and $97.2 \%$, respectively. The proportion of mediastinal nodal stations accessible by EBUS-TBNA was 78.6\%, and the proportion increased to $84.8 \%$ by combining EUS-B-FNA with EBUS-TBNA ( $p=0.015)$. EUS-B-FNA identified mediastinal metastasis in three additional patients.

In a recent prospective NSCLC staging trial in 146 patients, by OKI et al. [40], EBUS was routinely followed by EUS-B. The prevalence of mediastinal nodal metastases was $23 \%$. The sensitivities of EBUS, EUS-B, and the combination were $52 \%, 45 \%$ and $73 \%$, respectively, with negative predictive values of $88 \%$, $86 \%$ and $93 \%$, when using a surgical procedure (or clinical follow-up in a minority of patients) as the reference standard. The sub-centimetre size of the lymph nodes in combination with the low prevalence of malignancy might account for the low sensitivity of EBUS. Often small lymph nodes, especially in the left paratracheal station $4 \mathrm{~L}$, are more easily aspirated from the oesophagus. In coughing patients, getting a good sample out of these small lymph nodes with EBUS can be troublesome. In this study, patients were turned on their left side for EUS-B; it is questionable whether this is needed as EUS-B is mostly performed with patients in supine position [41]. 
TABLE 2 Studies that systematically assessed the accuracy of endobronchial ultrasound (EBUS) and endoscopic (oesophageal) ultrasound (EUS) for mediastinal staging in patients with (suspected) lung cancer

\begin{tabular}{|c|c|c|c|c|c|c|c|c|c|c|}
\hline \multirow[t]{2}{*}{ Study } & \multirow{2}{*}{$\begin{array}{l}\text { Reference } \\
\text { standard }\end{array}$} & \multirow[t]{2}{*}{ Test order } & \multirow{2}{*}{$\begin{array}{l}\text { Patients } \\
n\end{array}$} & \multirow{2}{*}{$\begin{array}{l}\text { Prevalence } \\
\text { N2/N3 \% }\end{array}$} & \multicolumn{2}{|c|}{ EBUS } & \multicolumn{2}{|c|}{ EUS } & \multicolumn{2}{|c|}{ EBUS+EUS } \\
\hline & & & & & $\begin{array}{l}\text { Sensitivity } \\
(95 \% \mathrm{CI})\end{array}$ & $\begin{array}{c}\text { NPV } \\
(95 \% \mathrm{Cl})\end{array}$ & $\begin{array}{l}\text { Sensitivity } \\
\text { (95\% CI) }\end{array}$ & $\begin{array}{c}\text { NPV } \\
(95 \% \mathrm{Cl})\end{array}$ & $\begin{array}{l}\text { Sensitivity } \\
(95 \% \mathrm{Cl})\end{array}$ & $\begin{array}{c}\text { NPV } \\
(95 \% \mathrm{Cl})\end{array}$ \\
\hline $\begin{array}{l}\text { VILmann [31], } \\
2005\end{array}$ & $\begin{array}{l}\text { Surgery: } \\
\text { Pulmonary resection } \\
\text { with lymph node } \\
\text { exploration } \\
\text { Clinical follow-up }\end{array}$ & EUS-EBUS & 28 & 71 & $0.85(0.62-0.97)$ & $0.72(0.39-0.94)$ & $0.80(0.56-0.94)$ & $0.67(0.35-0.90)$ & $1.00(0.83-1.00)$ & $1.00(0.63-1.00)$ \\
\hline $\begin{array}{l}\text { WALLACE [32], } \\
2008\end{array}$ & $\begin{array}{l}\text { Surgery: } \\
\text { Pulmonary resection } \\
\text { with mediastinal } \\
\text { exploration } \\
\text { Mediastinoscopy } \\
\text { Thoracoscopy } \\
\text { Clinical follow-up }\end{array}$ & EBUS-EUS & 138 & 30 & $0.69(0.53-0.82)$ & $0.88(0.80-0.93)$ & $0.69(0.53-0.82)$ & $0.88(0.80-0.93)$ & $0.93(0.81-0.99)$ & $0.97(0.91-0.99)$ \\
\hline $\begin{array}{l}\text { ANNEMA [18], } \\
2010\end{array}$ & $\begin{array}{l}\text { Surgery: } \\
\text { Pulmonary resection } \\
\text { with node } \\
\text { dissection }\end{array}$ & EUS-EBUS & 123 & 54 & - & - & - & - & $0.85(0.74-0.92)$ & $0.85(0.74-0.93)$ \\
\hline $\begin{array}{l}\text { HeRTH [33], } \\
2010\end{array}$ & $\begin{array}{l}\text { Surgery: } \\
\text { Thoracoscopy } \\
\text { Pulmonary resection } \\
\text { with node } \\
\text { dissection } \\
\text { Clinical follow-up }\end{array}$ & EBUS-EUS-B & 139 & 52 & $0.92(0.83-0.97)$ & $0.92(0.83-0.97)$ & $0.89(0.79-0.95)$ & $0.89(0.80-0.95)$ & $0.96(0.88-0.99)$ & $0.96(0.88-0.99)$ \\
\hline $\begin{array}{l}\text { HWANGBo [34], } \\
2010\end{array}$ & $\begin{array}{l}\text { Surgery: } \\
\text { Pulmonary resection } \\
\text { node dissection }\end{array}$ & EBUS-EUS-B & 143 & 31 & $0.84(0.71-0.94)$ & $0.93(0.87-0.97)$ & - & - & $0.91(0.79-0.98)$ & $0.96(0.90-0.99)$ \\
\hline $\begin{array}{l}\text { SzLUBowskI [35], } \\
2010\end{array}$ & $\begin{array}{l}\text { Surgery: } \\
\text { Pulmonary resection } \\
\text { with node } \\
\text { dissection } \\
\text { TEMLA }\end{array}$ & EUS-EBUS & 120 & 23 & $0.46(0.28-0.66)$ & $0.86(0.78-0.92)$ & $0.50(0.31-0.69)$ & $0.87(0.79-0.93)$ & $0.68(0.48-0.84)$ & $0.91(0.83-0.96)$ \\
\hline $\begin{array}{l}\text { OHNISHI [36], } \\
2011\end{array}$ & $\begin{array}{l}\text { Surgery: } \\
\text { Pulmonary resection } \\
\text { with nodal } \\
\text { exploration }\end{array}$ & EBUS-EUS & 110 & 28 & - & - & - & - & $0.84(0.71-0.97)$ & $0.94(0.89-0.99)$ \\
\hline
\end{tabular}




\begin{tabular}{|c|c|c|c|c|c|c|c|c|c|c|}
\hline \multirow[t]{2}{*}{ Study } & \multirow{2}{*}{$\begin{array}{l}\text { Reference } \\
\text { standard }\end{array}$} & \multirow[t]{2}{*}{ Test order } & \multirow{2}{*}{$\begin{array}{c}\text { Patients } \\
\text { n }\end{array}$} & \multirow{2}{*}{$\begin{array}{c}\text { Prevalence } \\
\text { N2/N3 \% }\end{array}$} & \multicolumn{2}{|c|}{ EBUS } & \multicolumn{2}{|c|}{ EUS } & \multicolumn{2}{|c|}{ EBUS+EUS } \\
\hline & & & & & $\begin{array}{c}\text { Sensitivity } \\
(95 \% \mathrm{Cl})\end{array}$ & $\begin{array}{c}\text { NPV } \\
(95 \% \mathrm{Cl})\end{array}$ & $\begin{array}{c}\text { Sensitivity } \\
(95 \% \mathrm{Cl})\end{array}$ & $\begin{array}{c}\text { NPV } \\
(95 \% \mathrm{Cl})\end{array}$ & $\begin{array}{c}\text { Sensitivity } \\
(95 \% \mathrm{Cl})\end{array}$ & $\begin{array}{c}\text { NPV } \\
(95 \% \mathrm{Cl})\end{array}$ \\
\hline $\begin{array}{c}\text { KANG [37], } \\
2014\end{array}$ & $\begin{array}{l}\text { Surgery: } \\
\text { Pulmonary resection } \\
\text { with node } \\
\text { dissection } \\
\text { Video-assisted } \\
\text { thoracic surgery }\end{array}$ & EBUS-EUS-B & 74 & 46 & - & - & - & - & $0.84(0.66-0.95)$ & $0.94(0.87-0.98)$ \\
\hline $\begin{array}{c}\text { KANG [37], } \\
2014\end{array}$ & $\begin{array}{l}\text { Surgery: } \\
\text { Pulmonary resection } \\
\text { with node } \\
\text { dissection } \\
\text { Video-assisted } \\
\text { thoracic surgery }\end{array}$ & EUS-B-EBUS & 74 & 34 & $0.82(0.65-0.93)$ & $0.87(0.74-0.95)$ & - & - & $0.85(0.69-0.95)$ & $0.89(0.76-0.96)$ \\
\hline $\begin{array}{l}\text { LeE [38], } \\
2014\end{array}$ & $\begin{array}{l}\text { Surgery: } \\
\text { Mediastinoscopy } \\
\text { Pulmonary resection } \\
\text { with mediastinal } \\
\text { node dissection }\end{array}$ & EBUS-EUS-B & 37 & 78 & $0.79(0.60-0.92)$ & $0.57(0.29-0.82)$ & - & - & $1.00(0.88-1.00)$ & $1.00(0.63-1.00)$ \\
\hline $\begin{array}{l}\text { LIBERMAN [39], } \\
2014\end{array}$ & $\begin{array}{l}\text { Surgery: } \\
\text { Mediastinoscopy } \\
\text { (no pulmonary } \\
\text { resection with } \\
\text { nodal exploration/ } \\
\text { dissection) }\end{array}$ & EBUS-EUS & 166 & 32 & $0.72(0.58-0.83)$ & $0.88(0.81-0.93)$ & $0.62(0.48-0.75)$ & $0.85(0.78-0.91)$ & $0.91(0.79-0.97)$ & $0.96(0.90-0.99)$ \\
\hline $\begin{array}{l}\text { OкІ [40], } \\
2014\end{array}$ & $\begin{array}{l}\text { Surgery: } \\
\text { Pulmonary resection } \\
\text { with node } \\
\text { exploration/ } \\
\text { dissection } \\
\text { Clinical follow-up }\end{array}$ & EBUS-EUS-B & 146 & 23 & $0.52(0.34-0.69)$ & $0.88(0.81-0.93)$ & $0.45(0.28-0.64)$ & $0.86(0.79-0.92)$ & $0.73(0.54-0.87)$ & $0.93(0.86-0.97)$ \\
\hline
\end{tabular}


LEE et al. [38] retrospectively analysed 37 cases in which EUS-B was performed in addition to EBUS when nodes were inaccessible by EBUS or when tissue sampling by EBUS alone was unsatisfactory. A reference standard of mediastinoscopy or mediastinal lymph node dissection was used. The sensitivity of EBUS compared with the combination was $79 \%$ versus $100 \%(\mathrm{p}=0.008)$, and in six patients $(13 \%)$ their disease was upstaged based on EUS-B findings.

In a study by Liberman et al. [39], 166 patients with (suspected) NSCLC underwent EBUS, EUS, and mediastinoscopy in the same setting. The prevalence of mediastinal metastases was $32 \%$. Against a reference standard of mediastinoscopy, the sensitivity and negative predictive values were: for EBUS, $72 \%$ and 88\%; for EUS, $62 \%$ and $85 \%$; and for combined EBUS/EUS, $91 \%$ and $96 \%$. Endosonography was diagnostic for $\mathrm{N} 2 / \mathrm{N} 3 / \mathrm{M} 1$ disease in 24 patients in whom mediastinoscopy findings were negative, preventing futile thoracotomy in $14 \%$ of patients [39].

The combination of EBUS-TBNA and EUS-FNA showed a pooled sensitivity of $86 \%$ (95\% CI $82 \%-90 \%$ ) with a $100 \%$ specificity for mediastinal nodal staging in a meta-analysis based on eight studies (821 patients) [25]. The sensitivity of the combined EBUS and EUS investigations appeared to be higher in the subgroup with mediastinal abnormalities, but pooled data were not provided. Although the authors concluded that "the current evidence suggests that the combined technique is more sensitive than EBUS-TBNA or EUS-FNA alone," they did not statistically compare results from individual tests with the combined approach.

Random-effects meta-analysis was performed to evaluate the increase in sensitivity provided by the combined approach. Adding EUS-(B)-FNA to EBUS-TBNA for mediastinal nodal staging in a series of patients with established or suspected lung cancer, showed an increase in sensitivity of $13 \%$ (95\% CI 8\%-20\%) for the combined approach compared with EBUS-TBNA alone (nine studies; fig. 2a). Adding EBUS-TBNA to EUS-(B)-FNA showed an increase in sensitivity of 21\% (95\% CI 13\%-30\%) for the combined approach compared with EUS-(B)-FNA alone (seven studies; fig. 2b). Assuming a prevalence of nodal metastasis of 50\%, these numbers would indicate that in 100 patients, adding EUS-(B)-FNA would avoid further surgical staging in an additional 6.5 cases not identified by initial EBUS-TBNA; conversely, adding EBUS-TBNA would avoid further surgical staging in an additional 10.5 cases not identified by initial EUS-(B)-FNA. Considering that the studies included in these meta-analyses are highly variable regarding quality and study population [25], that some studies included only patients with mediastinal lymph nodes that were not accessible by EBUS-TBNA, that a "complete" EBUS-TBNA or EUS-FNA was not always performed, that the reference standard included imperfect tests in some cases, and in the absence of randomised trials comparing complete staging in single tests with the combined approach, the results of this pooled analysis should be interpreted with caution.

\section{Safety}

Complications of endosonographic procedures are rare. In a 2014 systematic review on adverse events in 16181 patients undergoing endosonography for mediastinal, hilar or primary lung tumour analysis, 23 serious adverse events (0.14\%) were reported: $0.3 \%$ for EUS and $0.05 \%$ for EBUS [42]. A systematic review of 13 studies (1536 patients) that reported on the safety of EBUS-TBNA in lung cancer was published in 2009 [43]; no complications were reported in 11 studies, while one study reported no "major complication," and one study reported rare side-effects, notably cough. In a systematic review [25] of combined EUS-FNA and EUS-TBNA for the staging of mediastinal lymph nodes in lung cancer, severe complications were reported in 2 patients $(0.3 \%)$, consisting of pneumothorax and lymph node abscess [25]. A nationwide survey, by the Japan Society for Respiratory Endoscopy, of complications associated with EBUS-TBNA [44] found that, among 7345 procedures performed in 210 facilities, 90 complications occurred (complication rate $1.23 \%, 95 \%$ CI $0.97 \%-1.48 \%$ ), resulting in one patient death (mortality rate $0.01 \%)$. The most frequent complications were haemorrhage (55\%) and infection (16\%). The reported death was related to cerebral infarction during withdrawal of antiplatelet drugs (replaced by heparin).

\section{Cost-effectiveness}

In the only study that measured actual costs and took healthcare utilisation into account [18], endosonography followed by surgical staging in those with negative test findings proved to be cost-effective over surgical staging alone $[18,24]$. The cost-effectiveness gain at 6 months was mainly related to a statistically significant reduction of the post-staging utility with the surgical compared with the combined endoscopic approach, and with a reduction in the overall costs associated with the nonsurgical staging procedure. The higher costs in the "surgical" arm were due to the higher number of thoracotomies that had to be performed in this arm, and not due to mediastinoscopy itself.

In a simulated model of evaluation of lung cancer patients with different prevalences of mediastinal disease, a cost-minimisation analysis showed that the combination of EBUS-FNA/EUS-FNA would appear as the most cost-effective approach, compared with bronchoscopy and mediastinoscopy, when the expected prevalence of lymph node metastasis is higher than $32.9 \%$. This occurs in patients with a finding 
a)

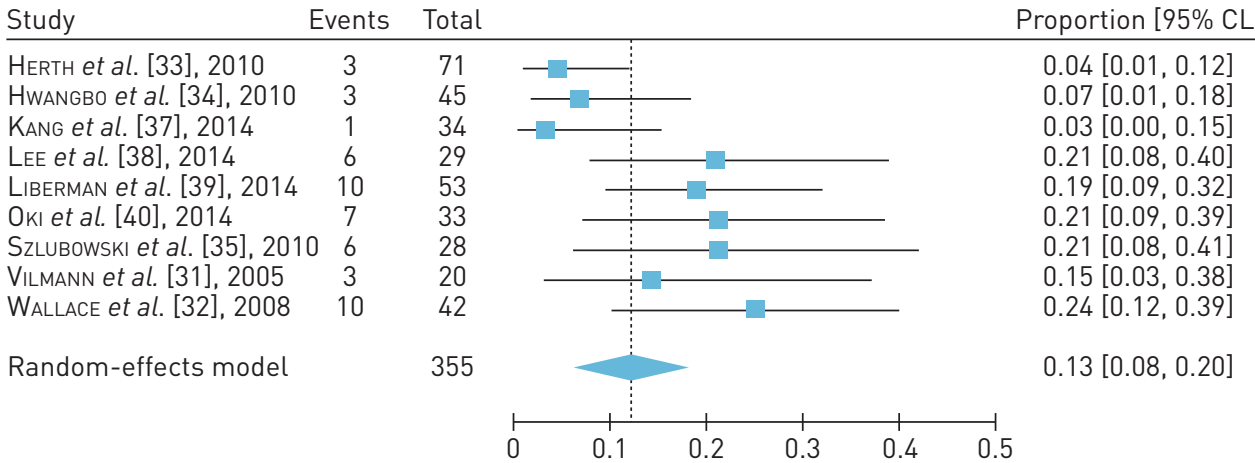

b) Study Events Total

Proportion $[95 \% \mathrm{CL}]$

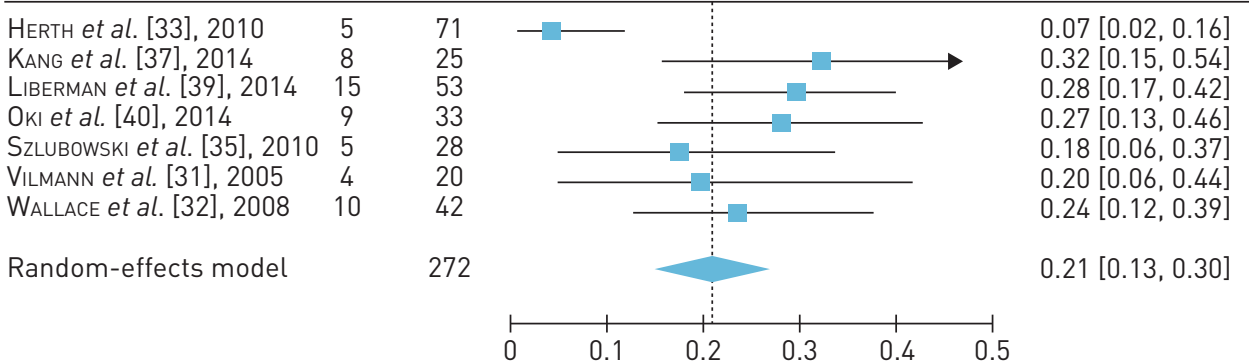

FIGURE 2 Endobronchial ultrasound with transbronchial needle aspiration (EBUS-TBNA) combined with endoscopic (oesophageal) ultrasound with real-time guided fine needle aspiration either using the conventional EUS endoscope or using the EBUS scope (that is, EUS-(B)-FNA) for mediastinal nodal staging: comparison of the sensitivity of a single test with that of the combined approach. a) Increase in sensitivity of the combined approach compared with EBUS-TBNA alone. b) Increase in sensitivity of the combined approach compared with EUS-(B)-FNA alone. Random-effects meta-analysis was performed to evaluate the increase in sensitivity of the combined approach versus a single test. The "events" columns show the numbers of cases that were detected by the combined approach, but not by a single test. The "total" columns show the total number of cases, as determined by the reference standard. The "proportion" column shows the increase in sensitivity of the combined approach versus the single test. a) A $13 \%$ (95\% confidence limits (CL) 8\%-20\%) increase in sensitivity from the combined approach over EBUS-TBNA or alone is suggested. b) A $21 \%(95 \%$ CL $13 \%-30 \%)$ increase in sensitivity from the combined approach over EUS-(B)-FNA alone is suggested. Study quality, especially the quality of the reference standard, and the patient populations of included studies vary considerably so the risk of bias may be substantial.

of abnormal mediastinum at radiological staging [45]. In that model, EUS-FNA alone appeared to be the most cost-effective approach if the prevalence of lymph node metastasis is lower than mentioned above, as well as in patients without abnormal lymph nodes on CT [45].

\section{Recommendation 2}

For mediastinal nodal staging in patients with suspected or proven non-small cell peripheral lung cancer without mediastinal involvement at CT or CT-PET, we suggest that EBUS-TBNA and/or EUS-(B)-FNA should be performed before therapy, provided that one or more of the following conditions is present: 1) enlarged or FDG-PET-avid ipsilateral hilar nodes; 2) primary tumour without FDG uptake; 3 ) tumour size $\geqslant 3 \mathrm{~cm}$; (fig. 3) (recommendation grade C).

If endosonography does not show malignant nodal involvement, we suggest that mediastinoscopy is considered, especially in suspected $\mathrm{N} 1$ disease (recommendation grade $\mathrm{C}$ ).

If PET is not available and CT does not reveal enlarged hilar or mediastinal lymph nodes, we suggest performance of EBUS-TBNA and/or EUS-FNA and/or surgical staging (recommendation grade C).

\section{Recommendation 3}

In patients with suspected or proven $<3 \mathrm{~cm}$ peripheral NSCLC with normal mediastinal and hilar nodes at CT and/or PET, we suggest initiation of therapy without further mediastinal staging (recommendation grade $\mathrm{C}$ ). 
a)

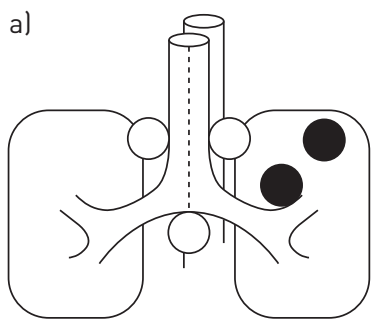

Peripheral lung cancer Normal mediastinum Ipsilateral hilar node Tumour $<3 \mathrm{~cm}$ b)

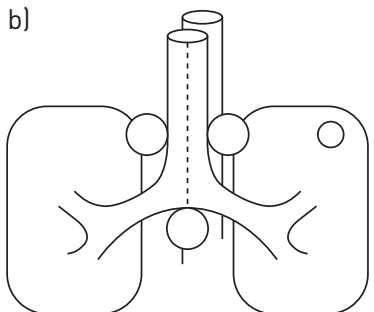

Peripheral lung cancer Normal mediastinum No FDG uptake in the tumour Tumour $<3 \mathrm{~cm}$

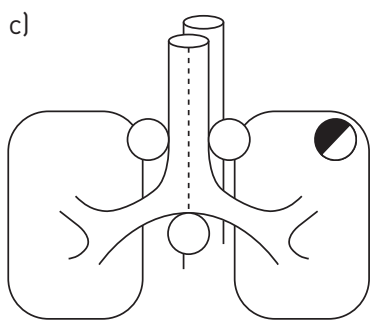

Peripheral lung cancer Normal mediastinum With or without FDG uptake in the tumour Tumour $\geqslant 3 \mathrm{~cm}$

FIGURE 3 Schematic representation of peripheral lung cancer with normal mediastinum and with: a) ipsilateral hilar node, and tumour $<3 \mathrm{~cm}$; b) no fluorodeoxyglucose (FDG) uptake in the tumour, and tumour $<3 \mathrm{~cm}$; $\mathrm{c}$ ) with or without FDG uptake in the tumour, and tumour $\geqslant 3 \mathrm{~cm}$.

\section{Background}

Patients with small mediastinal lymph nodes without increased FDG uptake present a $6 \%-30 \%$ risk of having mediastinal metastases in the following cases: 1) enlarged or FDG-avid hilar lymph nodes, or small and FDG-avid hilar lymph nodes; 2) any FDG-cold lung tumour (i.e. pulmonary carcinoid, pulmonary adenocarcinoma in situ; 3) lung tumour $>3 \mathrm{~cm}$ (mainly in the case of adenocarcinoma with high FDG uptake) without any lymph node involvement at CT or PET [9-11, 21, 46]. Mediastinal staging in those cases should be performed for accurate mediastinal nodal assessment in order to allocate patients appropriately for curative-intent therapy. Mediastinal lymph node metastases are present in less than $6 \%$ of patients with small peripheral tumours that present with neither enlarged nor FDG-avid hilar or mediastinal lymph nodes [27].

\section{Review of the studies}

Data on the accuracy of endosonography for staging in patients without mediastinal involvement on PET and/or CT are scarce. In two abovementioned meta-analyses [29, 30], the sensitivity for mediastinal nodal staging in the subgroup of patients regardless of, or without suspicious lymph nodes at CT or PET was $76 \%$ (95\% CI 65\%-85\%) for EBUS-TBNA (three studies, 263 patients) and 58\% (95\% CI 39\%-75\%) for EUS-FNA (four studies, 175 patients). Assuming a prevalence of $20 \%$, these numbers would indicate that 100 patients need to undergo endosonography to detect, respectively, 15.2 and 11.6 cases of mediastinal involvement in whom further surgical staging can be prevented. However, given the wide confidence intervals, especially for EUS, and the varying prevalence, these numbers should be interpreted with caution.

Further studies prospectively evaluated 100 consecutive patients with suspected resectable clinical N1 ( $\mathrm{cN} 1)$ disease, and a normal mediastinum, based on CT-PET with EBUS [47, 48]. The primary outcome was the sensitivity of endosonography to detect N2 disease, against a reference standard of histopathology. A total of 24 patients were diagnosed with N2 disease. The sensitivity from endosonography alone was $38 \%$ and this was increased to $73 \%$ by adding mediastinoscopy. So, in this population, 10 underwent mediastinoscopy to detect a single case with N2 disease missed by endosonography. In this study, EBUS was performed in all patients, while EUS was only added in patients with inaccessible or difficult-to-reach lymph nodes. However, in eight of the 14 false-negative cases where no EUS was performed, the affected nodes were well within the reach of EUS-(B), being stations $4 \mathrm{~L}, 7$, and 8. Should EUS-(B) have been routinely performed, the sensitivity of endosonography could have been above $70 \%[41,47]$.

According to a post hoc subgroup analysis of the ASTER trial [27], the prevalence of mediastinal metastases in patients without a suspicious mediastinum at CT-PET imaging was $26 \%$ and the sensitivity of combined EBUS and EUS staging was $71 \%$, although confidence intervals were wide (36\%-92\%) because of the small number of patients in this subgroup. In this subgroup of patients, the post-test probability for lymph node metastasis after a negative endosonography was $9 \%$ (95\% CI 4\%-24\%). After the addition of mediastinoscopy, the post-test probability remained unaffected [27]. In the surgical staging arm of the study, in patients with a non-suspicious mediastinum, the prevalence of mediastinal metastases was $17 \%$ and the sensitivity of surgical staging was $60 \%(90 \%$ CI $23 \%-88 \%)$, with a post-test probability of $8 \%(95 \%$ CI 3\%-19\%) after a negative test.

WALLACE et al. [32] described a subgroup of 60 patients with negative mediastinal findings at CT and PET who underwent both EBUS and EUS. The sensitivity and negative predictive value were $17 \%$ (95\% CI 2\%-48\%) 
and $83 \%$ for TBNA, 50\% (95\% CI 21\%-79\%) and 89\% for EBUS-TBNA, 67\% (95\% CI 35\%-90\%) and $92 \%$ for EUS-FNA, and 75\% (95\% CI 43\%-95\%) and 94\% for combined EBUS-EUS.

We found only one prospective study [35] that aimed to assess the diagnostic yield of the combined endosonographic approach in patients with NSCLC and a normal mediastinum on CT alone (stage IAIIB). A total of 120 patients underwent the combined approach with both EBUS-TBNA and EUS-FNA followed by transcervical extended bilateral mediastinal lymphadenectomy (TEMLA) and, if negative, pulmonary resection with dissection of the mediastinum as a confirmatory test. The overall sensitivity of the combined approach was $68 \%$, the negative predictive value was $91 \%$, and the positive predictive value was $91 \%$, at a prevalence of $\mathrm{N} 2 / \mathrm{N} 3$ disease of $22 \%$. In this study, 120 patients needed to undergo endosonography to detect 19 cases (16\%) in which further surgical staging could be prevented. Additional surgical staging in the remaining 101 patients identified another nine cases. The overall sensitivity of the combined technique was significantly higher than the sensitivity with EBUS alone (46\%, 95\% CI $28 \%-$ $65 \%)$ and also higher and close to the level of significance when compared with the sensitivity of EUS alone (50\%, 95\% CI 31\%-69\%).

\section{Recommendation 4}

For mediastinal staging in patients with centrally located suspected or proven NSCLC without mediastinal or hilar involvement at CT and/or CT-PET, we suggest performance of EBUS-TBNA, with or without EUS-(B)-FNA, in preference to surgical staging (fig. 4) (recommendation grade D).

If endosonography does not show malignant nodal involvement, mediastinoscopy may be considered (recommendation grade $\mathrm{D}$ ).

\section{Background}

According to the ESTS guidelines, for centrally located lung tumours exploration of mediastinal lymph nodes is indicated [21]. The false-negative rates of CT and PET imaging for mediastinal staging are high for patients with a centrally located lung tumour $(20 \%-25 \%$ and $24 \%-83 \%$, respectively) $[13,49]$.

\section{Review of the studies}

There are no diagnostic accuracy studies specifically focusing on the EBUS and EUS-(B) combination for patients with a centrally located lung tumour and a normal mediastinum/hilum. Therefore, recommendations are based on the evidence level of expert opinion.

The combination of EBUS-TBNA and EUS-(B)-FNA has been shown to have a high sensitivity and high negative predictive value in the staging of the mediastinal nodes. There are few studies in the literature about the role of endosonography for mediastinal staging of patients with a centrally located tumour [50, 51]. Moreover, it must be noted that there is no agreement in the studies concerning the definition of centrally located lung tumours. In a retrospective cohort of 16 patients who had EUS-FNA of lung mass lesions adjacent to or abutting the oesophagus, 10 patients had invasion of the mediastinum by the tumour as shown by EUS, defined as loss of interface between the tumour and the mediastinum, with an irregular border. Out of those 10 patients, six had mediastinal lymph nodes. EUS-FNA of the lymph nodes in three of those six patients did not yield a preliminary diagnosis after three needle passes. It was technically difficult to assess the mediastinal lymph nodes in the other three patients, because the lung mass was in close proximity and precluded lymph node access [50]. In another study, out of 17 patients undergoing EUS-FNA of a centrally located primary lung neoplasm, EUS identified metastatic lymph node involvement in three [51]. The accuracy of EBUS only for mediastinal staging has already been addressed above [29].

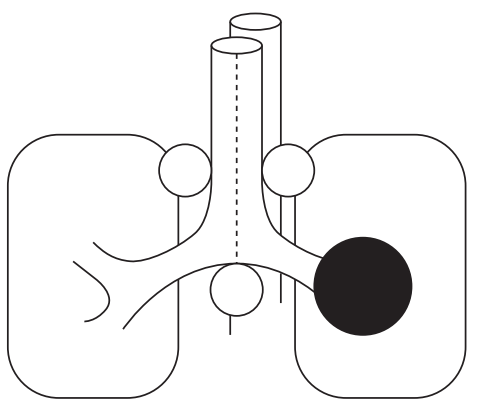

Centrally located lung cancer Normal mediastinum
FIGURE 4 Schematic representation of centrally located lung cancer with normal mediastinum. 


\section{Recommendation 5}

For mediastinal nodal restaging following neoadjuvant therapy, EBUS-TBNA and/or EUS-(B)-FNA is suggested for detection of persistent nodal disease, but, if this is negative, subsequent surgical staging is indicated (Recommendation grade $\mathrm{C}$ ).

\section{Background}

According to current guidelines, stage III NSCLC (N2/N3), that is, with metastatic involvement of the ipsilateral (stage IIIA-N2) or contralateral (stage IIIB-N3) mediastinal lymph nodes, should be treated with chemoradiation therapy $[22,52]$. The role of surgery in stage III $(\mathrm{N} 2 / \mathrm{N} 3)$ disease is under debate. It has been shown that patients whose disease is downstaged to N0 with chemoradiation therapy, and who subsequently undergo complete surgical resection of the lung tumour, have improved survival in comparison to those patients who undergo surgery with persistent nodal disease [53, 54]. Therefore, if surgery is being considered following chemoradiation therapy, adequate nodal restaging is essential to identify those patients whose disease has downstaged to N0.

\section{Review of the studies}

\section{EUS studies}

In 2003, ANNEma et al. [55] published the first case study with EUS-FNA for mediastinal restaging in 19 NSCLC patients with N2 disease who had been treated with induction chemotherapy. In the absence of regional lymph node metastasis (N0) at EUS-FNA, surgical resection of the tumour with lymph node sampling or dissection was performed. A sensitivity, negative predictive value and diagnostic accuracy of $75 \%, 67 \%$ and $83 \%$, respectively, were found.

In a retrospective study that included 14 patients with NSCLC and biopsy-proven N2 disease, restaging by EUS-FNA following chemoradiation therapy had an $86 \%$ diagnostic accuracy for predicting mediastinal response [56].

In a prospective study in 28 patients, STIGT et al. [57] re-evaluated the mediastinum after induction therapy, and found a negative predictive value of $91.6 \%$ and accuracy of $92.3 \%$.

VON BARTHELD et al. [58] retrospectively analysed 58 consecutive patients with tissue-proven stage IIIA-N2 or IIIB-N3 NSCLC who underwent EUS-FNA for mediastinal restaging after neoadjuvant chemoradiation therapy. Sensitivity, negative predictive value, false-negative rate and accuracy of EUS-FNA for mediastinal restaging were $44 \%, 42 \%, 58 \%$ and $60 \%$, respectively. A large percentage (22\%) of nodal metastases found at surgery were in locations beyond the reach of EUS.

In a recent retrospective restaging study, EUS and/or EBUS was performed in 88 patients followed by TEMLA if results were negative $(\mathrm{n}=78)$. Significant differences were found between EBUS or EUS and TEMLA for sensitivity $(64.3 \%$ and $100 \%$; $<<0.01)$ and negative predictive value $(82.1 \%$ and $100 \%$; $<<0.01)$, in favour of TEMLA [59].

\section{EBUS studies}

HERTH et al. [60] retrospectively investigated EBUS-TBNA for restaging the mediastinum following induction chemotherapy in 124 patients with NSCLC. Overall sensitivity, specificity, positive and negative predictive values, and diagnostic accuracy of EBUS-TBNA for mediastinal restaging after induction chemotherapy were $76 \%, 100 \%, 100 \%, 20 \%$ and $77 \%$, respectively.

SZLUBOWSKI et al. [61] retrospectively analysed a group of 61 consecutive NSCLC patients with pathologically confirmed N2 disease who underwent neoadjuvant chemotherapy, and in whom EBUS-TBNA was performed for restaging. The sensitivity and negative predictive value of the restaging EBUS-TBNA were $67 \%$ and $78 \%$, respectively. Recently, SzLubowsKi et al. [62] prospectively assessed the diagnostic utility of combined EBUS-TBNA and EUS-B-FNA for NSCLC restaging after induction therapy in 106 patients with pathologically proven N2 disease. The prevalence of persistent mediastinal lymph node metastases was $51.9 \%$ and the sensitivity, specificity, total accuracy, and positive and negative predictive values of the combined approach were $67.3 \%, 96.0 \%, 81.0 \%, 95.0 \%$ and $73.0 \%$, respectively. The overall accuracy of the combined approach was higher as compared with EBUS-TBNA and EUS-FNA alone.

\section{Recommendation 6}

A complete assessment of mediastinal and hilar nodal stations, and sampling of at least three different mediastinal nodal stations (4R, 4L,7) (figs 1 and 5) is suggested in patients with NSCLC and an abnormal mediastinum by CT or CT-PET (recommendation grade D). 


\section{Background}

For surgical nodal staging by mediastinoscopy, clear recommendations have been made regarding the number and nodes to be sampled [21,22]. For endosonography, there is no agreement about how many and which lymph node stations should be sampled and which level of thoroughness is necessary for different situations. Some advise a thorough evaluation of all lymph nodes detectable by EBUS and EUS followed by sampling. In many centres, however, the so-called "hit and run" approach is followed, where only the lymph nodes that are suspicious at CT-PET imaging are sampled.

In the recent guidelines from the American College of Chest Physicians (ACCP) [22], a classification of levels of thoroughness has been developed and could serve as a guide. Four approaches were proposed: A, complete sampling of each node in each major mediastinal node station $(2 \mathrm{R}, 4 \mathrm{R}, 2 \mathrm{~L}, 4 \mathrm{~L}, 7$, and possibly 5 or 6); B, systematic sampling of each node station; C, selective sampling of suspicious nodes only; or D, very limited or no sampling, with only visual assessment.

In line with the ESTS guidelines [21], we recommend that at least three stations should be assessed (subcarinal, left paratracheal and right paratracheal) and biopsy samples should be taken if possible with EBUS, EUS or mediastinoscopy. Furthermore, all other abnormal lymph nodes, identified by size or FDG avidity, should be sampled. This "complete" mediastinal staging is based on the concept that identification of one malignant lymph node does not mean that mediastinal staging was optimal.

\section{Recommendation 7}

For diagnostic purposes, in patients with a centrally located lung tumour that is not visible at conventional bronchoscopy, endosonography is suggested, provided the tumour is located immediately adjacent to the larger airways (EBUS) or oesophagus (EUS-(B)) (recommendation grade D).

To date, there are limited studies regarding the role of EUS-FNA and EBUS-TBNA in the diagnosis of lung parenchymal masses. A recent retrospective study [63] assessed the diagnostic yield and safety of EUS-FNA of central mediastinal lung masses. In 11 out of 73 patients, the lung mass could not be visualised by EUS. The sensitivity of EUS was $96.7 \%$ when only the visualised masses were considered, but this value dropped to $80.8 \%$ when the 11 nonvisualised masses were also taken into account. AnNema et al. [64] conducted a prospective study with 32 patients to assess the feasibility and diagnostic yield of EUS-FNA for the diagnosis of centrally located lung tumours following a nondiagnostic bronchoscopy. EUS-FNA provided a diagnosis of malignancy in $97 \%$ of patients. In $39 \%$ of the patients, EUS-FNA not only established the diagnosis of lung cancer, but also staged patients as having T4 disease, based on tumour invasion; however, the latter was not verified surgically. None of the included patients had mediastinal lymph node involvement at CT scan [64]. VARADARAJUlu et al. [50] conducted a retrospective study including 18 patients who had undergone EUS-FNA of a lung mass abutting the oesophageal wall. A diagnosis was obtained in all patients. HERNANDEZ et al. [51] retrospectively described their experience with EUS-FNA of centrally located primary lung cancers; 17 patients had FNA of both the lung mass and the mediastinal lymph nodes, and all procedures provided an accurate diagnosis of the primary lung lesion.

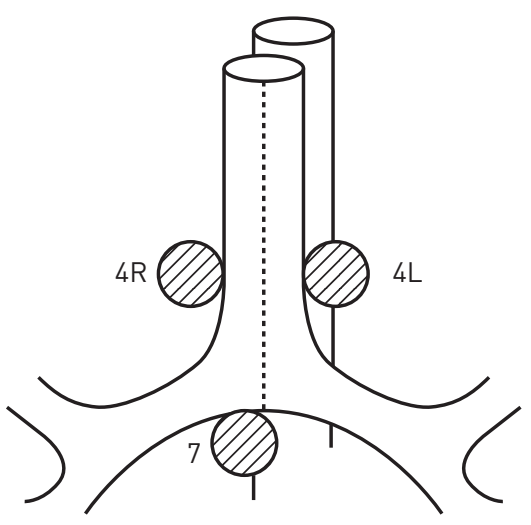


In a retrospective noncomparative study including 60 patients with a central parenchymal lung lesion suspected to be lung cancer ( $82 \%$ with a prior nondiagnostic flexible bronchoscopy), Tournoy et al. [65] demonstrated that the sensitivity of EBUS-TBNA was $82 \%$ with a negative predictive value of $23 \%$. An exploratory analysis showed that the sensitivity for small versus large lesions, when a short-axis cut-off was arbitrarily set at $25 \mathrm{~mm}$, was $78 \%$ (95\% CI 57\%-91\%) versus $86 \%$ (95\% CI 68\%-96\%), respectively $(\mathrm{p}=0.50)$. Verma et al. [15] also recently demonstrated in 37 patients that EBUS-TBNA is an effective way (overall sensitivity $91.4 \%$ ) to diagnose parenchymal lesions located centrally close to the airways.

\section{Recommendation 8}

In patients with a left adrenal gland suspected for distant metastasis, we suggest performance of EUS-FNA (recommendation grade C), while the use of EUS-B with a transgastric approach is at present experimental (recommendation grade $\mathrm{D}$ ).

\section{Background}

The adrenal glands are a predilection site for lung cancer metastases. Distant metastases have significant impact on prognosis and treatment. Adrenal metastases originating from NSCLC have been found in approximately $10 \%-59 \%$ of patients in autopsy series [66].

FDG-PET-CT has a high accuracy (sensitivity of $94 \%$ and specificity of $85 \%$ ) for adrenal metastases in patients with lung cancer [67]. However, adrenal glands that are suspicious at FDG-PET-CT can be false-positive [68] and, therefore, tissue verification is indicated to either confirm or rule out metastatic spread in order to prevent PET/CT-based upstaging in patients.

Traditionally, adrenal masses have been sampled by percutaneous biopsy. A small study involving only 15 patients reported sensitivity and negative predictive value for adrenal biopsy of $73 \%$ and $60 \%$, respectively [69]. A study involving 79 patients reported an overall complication rate for percutaneous adrenal biopsies of $8.4 \%$ [70], including haemorrhage, pneumothorax, pancreatitis, adrenal abscesses, bacteraemia, and needle-tract metastases. Transgastric EUS-guided FNA can be performed during the same session as a mediastinal staging procedure, using the same endoscope.

\section{Review of the studies}

In 1996, CHANG et al. [71] reported the first application of EUS and EUS-FNA for left adrenal gland analysis and found that the left adrenal gland was visualised in 30 out of 31 patients (97\%).

In 31 patients with suspected thoracic or gastrointestinal malignancies and enlarged left adrenal gland on abdominal imaging (including 15 patients with lung cancer), ELoubEIDI et al. [72] reported that EUS-FNA obtained adequate tissue from the left adrenal gland in all patients.

In a mixed series of 119 patients with gastrointestinal or pulmonary disease, who underwent EUS with or without FNA, the left adrenal gland was routinely examined. The overall prevalence of a left adrenal mass was four out of $119(3.4 \%)$, all detected in the cohort of patients $(n=12)$ with lung cancer [73]. In a retrospective analysis of 40 patients, with established or suspected lung cancer and an enlarged left adrenal gland shown at EUS, the diagnostic yield of EUS-FNA for detecting left adrenal metastases was 95\% [74].

In a retrospective analysis by SCHUURBIERs et al. [75] of 85 patients with (suspected) lung cancer and a left adrenal gland suspicious for metastasis identified by CT and/or FDG-PET, EUS-FNA demonstrated left adrenal metastases in $62 \%$ and benign adrenal tissue in $29 \%$. Sensitivity and negative predictive value for EUS-FNA of the left adrenal gland were at least $86 \%$ (95\% CI 74\%-93\%) and 70\% (95\% CI 50\%-85\%), respectively. No complications occurred.

ELOUBEIDI et al. [76] evaluated 59 patients with enlarged adrenal gland(s) on abdominal CT, magnetic resonance imaging (MRI), and/or PET, and known or suspected malignancy. All patients underwent EUS-guided FNA (54 left adrenal gland and five right adrenal gland), and adrenal tissue adequate for interpretation was obtained in all patients. On multivariable analysis, altered adrenal gland shape (loss of seagull configuration) was a significant predictor of malignancy.

Most literature about EUS of the adrenal gland concerns the left adrenal gland. However, there are some reports about transduodenal EUS-guided FNA of the right adrenal gland. It seems feasible and safe in experienced hands [77-79].

Recently, UEMURA et al. [79] retrospectively analysed a consecutive series of 150 patients with potentially resectable lung cancer who were undergoing EUS/EUS-FNA for mediastinal staging of lung cancer. Routinely, both the left and right adrenal glands were assessed. The left adrenal gland was visualised in all patients (100\%) and the right adrenal gland in $87.3 \%$ of patients. Transgastric analysis and FNA of the left 
adrenal gland using an EBUS scope has been described [77], but its feasibility and safety are under investigation.

Complications of EUS-guided FNA of adrenal glands are rare; an adrenal haemorrhage has been described [80]. However, it should be emphasised that, in the case of signs of a pheochromocytoma, endocrinologic evaluation must be done prior to endosonography.

\section{Recommendation 9}

For optimal endosonographic staging of lung cancer, we suggest that individual endoscopists should be trained in both EBUS and EUS-B, in order to perform complete endoscopic staging in one session (recommendation grade $\mathrm{D}$ ).

\section{Background}

The quality and safety of endosonography is very dependent on the skills and experience of the operator. Diagnostic yield improves with practice [81], and the number of complications is also associated with operator experience [82]. Despite this, there is a paucity of evidence-based structured training programmes, and the important decision about when a trainee is considered competent is often based on an arbitrary number of performed procedures or on subjective impressions.

As the combined staging by EBUS and EUS is superior to staging by a single technique [25], it seems logical that the skills should be present in a single operator [83]. For practical and economic reasons, the majority of procedures will be performed with EBUS scopes for both the endobronchial and oesophageal route.

\section{Recommendation 10}

We suggest that new trainees in endosonography should follow a structured training curriculum consisting of simulation-based training followed by supervised practice on patients (recommendation grade D).

\section{Background}

Increased focus on patient safety has put pressure on the traditional apprenticeship model where trainees under supervision practice on patients. Simulation-based training, on phantoms and virtual reality devices, has been suggested for helping trainees surmount the initial, steep part of the learning curve.

\section{Review of the studies}

A systematic review and meta-analysis regarding technology-enhanced simulation, based on 609 papers, found "large effects for outcomes of knowledge, skills, and behaviours and moderate effects for patient-related outcomes" [84]. There are two virtual reality simulators commercially available for EBUS: the GI Bronch Mentor (Simbionix, Cleveland, Ohio, USA) and the AccuTouch Flexible Bronchoscopy Simulator (CAE Healthcare, Montreal, QC, Canada). Both simulators can discriminate between novices and experienced operators (indicating construct validity) $[85,86]$, but there are no published studies exploring the effect of EBUS simulator training on patient care. No software exists for mediastinal sampling using EUS, but EUS-FNA as well as EBUS-TBNA can be practiced on rubber models, animal organs, or live anaesthetised animals. A study regarding EBUS-TBNA training found both computer simulation and wet lab simulation to be effective and complementary [87].

However, despite the positive effects of simulation-based training, it is important to remember that no existing simulators are $100 \%$ realistic and not all aspects of a procedure can be practised. Supervised performance during initial patient encounters is essential, even after a thorough simulation-based training programme; self-learning of endosonography should be discouraged [88].

\section{Recommendation 11}

We suggest that competency in EBUS-TBNA and EUS-(B)-FNA for staging lung cancer be assessed using available validated assessment tools (recommendation grade $\mathrm{D}$ ).

\section{Background}

Thorough knowledge of (endosonographic) anatomy and its relation to the TNM lung cancer staging system is crucial for the performance of an endosonographic evaluation. Upstaging could prevent the patient from receiving potentially curative therapy, and downstaging may cause the patient to undergo unnecessary surgery and treatments without therapeutic benefit [89]. To avoid this, basic competency must be ensured before trainees are allowed to perform procedures independently. 
Review of the studies

Early guidelines for gastrointestinal EUS recommend a minimum of 150 total supervised procedures [90], but a more recent study on learning curves showed "substantial variability in achieving competency and a consistent need for more supervision than current recommendations" [91]. It is generally agreed that sampling in the mediastinum is technically easier than in other locations [92] and a study showed that chest physicians achieved satisfactory results after participating in an EUS implementation programme for staging lung cancer patients [93]. The only study exploring learning curves for EUS-FNA for lung cancer staging found that acquisition of skills varied between individuals and that 20 procedures were not enough to ensure basic competency [94].

Early guidelines on training requirements for EBUS from the American Thoracic Society/ERS and the ACCP respectively recommend minimum numbers of 40 and 50 procedures for initial acquisition of competence $[95,96]$. These numbers are based on expert opinions, are arbitrary, and are debated [89, 97]. Studies on EBUS learning curves have shown that performance of 50 procedures does not ensure basic competency [60, 95], and the latest guidelines from the British Thoracic Society recognise that "Individuals have different learning curves and hence focus should be towards monitoring an individual's performance and outcomes" [98]. Specific tools for assessment of performance in endosonography [99, 100] could be used for monitoring trainees' progression, and all programmes should continuously monitor their outcomes.

These guidelines from the ESGE, ERS and ESTS represent a consensus of best practice based on the available evidence at the time of preparation. They may not apply in all situations and should be interpreted in the light of specific clinical situations and resource availability. Further controlled clinical studies may be needed to clarify aspects of the statements, and revision may be necessary as new data appear. Clinical consideration may justify a course of action at variance to these recommendations. ESGE guidelines are intended to be an educational device to provide information that may assist endoscopists in providing care to patients. They are not rules and should not be construed as establishing a legal standard of care or as encouraging, advocating, requiring or discouraging any particular treatment.

\section{Acknowledgement}

The contribution of Paul Frost Clementsen in creating the artwork for figure 1 and figures 3-5 is gratefully acknowledged.

\section{References}

1 Ferlay J, Steliarova-Foucher E, Lortet-Tieulent J, et al. Cancer incidence and mortality patterns in Europe: estimates for 40 countries in 2012. Eur J Cancer 2013; 49: 1374-1403.

2 Rivera MP, Mehta AC, American College of Chest Physicians. Initial diagnosis of lung cancer: ACCP evidence-based clinical practice guidelines (2nd edition). Chest 2007; 132: 131S-148S.

3 Vansteenkiste J, De Ruysscher D, Eberhardt WE, et al. Early and locally advanced non-small-cell lung cancer (NSCLC): ESMO Clinical Practice Guidelines for diagnosis, treatment and follow-up. Ann Oncol 2013; 24: Suppl. 6, 89-98.

4 Libshitz HI, McKenna RJ Jr. Mediastinal lymph node size in lung cancer. AJR Am J Roentgenol 1984; 143 $715-718$.

5 Lardinois D, Weder W, Hany TF, et al. Staging of non-small-cell lung cancer with integrated positron-emission tomography and computed tomography. NEJM 2003; 348: 2500-2507.

6 Tournoy KG, Maddens S, Gosselin R, et al. Integrated FDG-PET/CT does not make invasive staging of the intrathoracic lymph nodes in non-small cell lung cancer redundant: a prospective study. Thorax 2007; 62: 696-701.

7 De Wever W, Stroobants S, Coolen J, et al. Integrated PET/CT in the staging of nonsmall cell lung cancer: technical aspects and clinical integration. Eur Respir J 2009; 33: 201-212.

8 Fischer BM, Mortensen J, Hansen H, et al. Multimodality approach to mediastinal staging in non-small cell lung cancer. Faults and benefits of PET-CT: a randomised trial. Thorax 2011; 66: 294-300.

9 Hishida T, Yoshida J, Nishimura M, et al. Problems in the current diagnostic standards of clinical N1 non-small cell lung cancer. Thorax 2008; 63: 526-531.

10 Watanabe S, Asamura $\mathrm{H}$, Suzuki $\mathrm{K}$, et al. Problems in diagnosis and surgical management of clinical N1 non-small cell lung cancer. Ann Thorac Surg 2005; 79: 1682-1685.

11 Cerfolio RJ, Bryant AS, Ojha B, et al. Improving the inaccuracies of clinical staging of patients with NSCLC: a prospective trial. Ann Thorac Surg 2005; 80: 1207-1213.

12 Cerfolio RJ, Bryant AS, Eloubeidi MA. Routine mediastinoscopy and esophageal ultrasound fine-needle aspiration in patients with non-small cell lung cancer who are clinically N2 negative: a prospective study. Chest 2006; 130: 1795-1795.

13 Detterbeck FC, Jantz MA, Wallace M, et al. Invasive mediastinal staging of lung cancer: ACCP evidence-based clinical practice guidelines (2nd edition). Chest 2007; 132: 202S-220S.

14 Pedersen BH, Vilmann P, Folke K, et al. Endoscopic ultrasonography and real-time guided fine-needle aspiration biopsy of solid lesions of the mediastinum suspected of malignancy. Chest 1996; 110: 539-544.

15 Verma A, Jeon K, Koh WJ, et al. Endobronchial ultrasound-guided transbronchial needle aspiration for the diagnosis of central lung parenchymal lesions. Yonsei Med J 2013; 54: 672-678.

16 Silvestri GA, Hoffman BJ, Bhutani MS, et al. Endoscopic ultrasound with fine-needle aspiration in the diagnosis and staging of lung cancer. Ann Thorac Surg 1996; 61: 1441-1445. 
Vilmann P, Annema J, Clementsen P. Endosonography in bronchopulmonary disease. Best Pract Res Clin Gastroenterol 2009; 23: 711-728.

Annema JT, van Meerbeeck JP, Rintoul RC, et al. Mediastinoscopy vs endosonography for mediastinal nodal staging of lung cancer: a randomized trial. JAMA 2010; 304: 2245-2252.

Wiersema MJ, Vilmann P, Giovannini M, et al. Endosonography-guided fine-needle aspiration biopsy: diagnostic accuracy and complication assessment. Gastroenterology 1997; 112: 1087-1095.

Herth FJ, Eberhardt R, Vilmann P, et al. Real-time endobronchial ultrasound guided transbronchial needle aspiration for sampling mediastinal lymph nodes. Thorax 2006; 61: 795-798.

De Leyn P, Dooms C, Kuzdzal J, et al. Revised ESTS guidelines for preoperative mediastinal lymph node staging for non-small-cell lung cancer. Eur J Cardiothorac Surg 2014; 45: 787-798.

Silvestri GA, Gonzalez AV, Jantz MA, et al. Methods for staging non-small cell lung cancer: Diagnosis and management of lung cancer, 3rd ed: American College of Chest Physicians evidence-based clinical practice guidelines. Chest 2013; 143: Suppl. 5, e211S-e250S.

Rintoul RC, Glover MJ, Jackson C, et al. Cost effectiveness of endosonography versus surgical staging in potentially resectable lung cancer: a health economics analysis of the ASTER trial from a European perspective. Thorax 2014; 69: 679-681.

Sharples LD, Jackson C, Wheaton E, et al. Clinical effectiveness and cost-effectiveness of endobronchial and endoscopic ultrasound relative to surgical staging in potentially resectable lung cancer: results from the ASTER randomised controlled trial. Health Technol Assess 2012; 16: 1-75.

Zhang R, Ying K, Shi L, et al. Combined endobronchial and endoscopic ultrasound-guided fine needle aspiration for mediastinal lymph node staging of lung cancer: a meta-analysis. Eur J Cancer 2013; 49: 1860-1867.

Scottish Intercollegiate Guidelines Network. Sign Grading System. www.sign.ac.uk/guidelines/fulltext/50/ annexoldb.html Date last updated: May 16, 2014.

Tournoy KG, Keller SM, Annema JT. Mediastinal staging of lung cancer: novel concepts. Lancet Oncol 2012; 13: e221-e229.

Darling GE, Maziak DE, Inculet RI, et al. Positron emission tomography-computed tomography compared with invasive mediastinal staging in non-small cell lung cancer: results of mediastinal staging in the early lung positron emission tomography trial. J Thorac Oncol 2011; 6: 1367-1372.

Gu P, Zhao YZ, Jiang LY, et al. Endobronchial ultrasound-guided transbronchial needle aspiration for staging of lung cancer: a systematic review and meta-analysis. Eur J Cancer 2009; 45: 1389-1396.

Micames CG, McCrory DC, Pavey DA, et al. Endoscopic ultrasound-guided fine-needle aspiration for non-small cell lung cancer staging: a systematic review and metaanalysis. Chest 2007; 131: 539-548.

Vilmann P, Krasnik M, Larsen SS, et al. Transesophageal endoscopic ultrasound-guided fine-needle aspiration (EUS-FNA) and endobronchial ultrasound-guided transbronchial needle aspiration (EBUS-TBNA) biopsy: a combined approach in the evaluation of mediastinal lesions. Endoscopy 2005; 37: 833-839.

Wallace MB, Pascual JM, Raimondo M, et al. Minimally invasive endoscopic staging of suspected lung cancer. JAMA 2008; 299: 540-546.

Herth FJ, Krasnik M, Kahn N, et al. Combined endoscopic-endobronchial ultrasound-guided fine-needle aspiration of mediastinal lymph nodes through a single bronchoscope in 150 patients with suspected lung cancer. Chest 2010; 138: 790-794.

Hwangbo B, Lee GK, Lee HS, et al. Transbronchial and transesophageal fine-needle aspiration using an ultrasound bronchoscope in mediastinal staging of potentially operable lung cancer. Chest 2010; 138: 795-802.

Szlubowski A, Zieliński M, Soja J, et al. A combined approach of endobronchial and endoscopic ultrasound-guided needle aspiration in the radiologically normal mediastinum in non-small-cell lung cancer staging - a prospective trial. Eur J Cardiothorac Surg 2010; 37: 1175-1179.

Ohnishi R, Yasuda I, Kato T, et al. Combined endobronchial and endoscopic ultrasound-guided fine needle aspiration for mediastinal nodal staging of lung cancer. Endoscopy 2011; 43: 1082-1089.

Kang HJ, Hwangbo B, Lee GK, et al. EBUS-centred versus EUS-centred mediastinal staging in lung cancer: a randomised controlled trial. Thorax 2014; 69: 261-268.

Lee KJ, Suh GY, Chung MP, et al. Combined endobronchial and transesophageal approach of an ultrasound bronchoscope for mediastinal staging of lung cancer. PLoS One 2014; 9: e91893.

Liberman M, Sampalis J, Duranceau A, et al. Endosonographic mediastinal lymph node staging of lung cancer. Chest 2014; 146: 389-397.

Oki M, Saka H, Ando M, et al. Endoscopic ultrasound-guided fine needle aspiration and endobronchial ultrasound-guided transbronchial needle aspiration: are two better than one in mediastinal staging of non-small cell lung cancer? J Thorac Cardiovasc Surg 2014; 148: 1169-1177.

Annema JT. Size matters. J Thorac Cardiovasc Surg 2015; 149: 942.

von Bartheld MB, van Breda A, Annema JT. Complication rate of endosonography (endobronchial and endoscopic ultrasound): a systematic review. Respiration 2014; 87: 343-351.

Varela-Lema L, Fernandez-Villar A, Ruano-Ravina A. Effectiveness and safety of endobronchial ultrasound-transbronchial needle aspiration: a systematic review. Eur Respir J 2009; 33: 1156-1164.

Asano F, Aoe M, Ohsaki Y, et al. Complications associated with endobronchial ultrasound-guided transbronchial needle aspiration: a nationwide survey by the Japan Society for Respiratory Endoscopy. Respir Res 2013; 14: 50

Harewood GC, Pascual J, Raimondo M, et al. Economic analysis of combined endoscopic and endobronchial ultrasound in the evaluation of patients with suspected non-small cell lung cancer. Lung Cancer 2010; 67: 366-371. Toloza E, Harpole L, Detterbeck F, et al. Invasive staging of non-small cell lung cancer: a review of the current evidence. Chest 2003; 123: Suppl. 1, S157-S166.

Dooms C, Tournoy KG, Schuurbiers O, et al. Endosonography for mediastinal nodal staging of clinical N1 non-small cell lung cancer: a prospective multicenter study. Chest 2015; 147: 209-215.

Annema JT. When will we finally adopt endoscopic ultrasound? Chest 2014; 146: e117.

Ghosh S, Nanjiah P, Dunning J. Should all patients with non-small cell lung cancer who are surgical candidates have cervical mediastinoscopy preoperatively? Interact Cardiovasc Thorac Surg 2006; 5: 20-24.

Varadarajulu S, Hoffman BJ, Hawes RH, et al. EUS-guided FNA of lung masses adjacent to or abutting the esophagus after unrevealing CT-guided biopsy or bronchoscopy. Gastrointest Endosc 2004; 60: 293-297. 
51 Hernandez A, Kahaleh M, Olazagasti J, et al. EUS-FNA as the initial diagnostic modality in centrally located primary lung cancers. J Clin Gastroenterol 2007; 41: 657-660.

52 Vansteenkiste J, De Ruysscher D, Eberhardt WE, et al. Early and locally advanced non-small-cell lung cancer (NSCLC): ESMO Clinical Practice Guidelines for diagnosis, treatment and follow-up. Ann Oncol 2013; 24: Suppl. 6, vi89-vi98.

53 de Cabanyes CS, Detterbeck FC. A systematic review of restaging after induction therapy for stage IIIa lung cancer: prediction of pathologic stage. J Thorac Oncol 2010; 5: 389-398.

54 De Leyn P, Stroobants S, De Wever W, et al. Prospective comparative study of integrated positron emission tomography-computed tomography scan compared with remediastinoscopy in the assessment of residual mediastinal lymph node disease after induction chemotherapy for mediastinoscopy-proven stage IIIA-N2 non-small-cell lung cancer: a Leuven Lung Cancer Group Study. J Clin Oncol 2006; 24: 3333-3339.

55 Annema JT, Veselic M, Versteegh MI, et al. Mediastinal restaging: EUS-FNA offers a new perspective. Lung Cancer 2003; 42: 311-318.

56 Varadarajulu S, Eloubeidi M. Can endoscopic ultrasonography-guided fine-needle aspiration predict response to chemoradiation in non-small cell lung cancer? A pilot study. Respiration 2006; 73: 213-220.

57 Stigt JA, Oostdijk AH, Timmer PR, et al. Comparison of EUS-guided fine needle aspiration and integrated PET-CT in restaging after treatment for locally advanced non-small cell lung cancer. Lung Cancer 2009; 66: 198-204.

58 von Bartheld MB, Versteegh MI, Braun J, et al. Transesophageal ultrasound-guided fine-needle aspiration for the mediastinal restaging of non-small cell lung cancer. J Thorac Oncol 2011; 6: 1510-1515.

59 Zielinski M, Szlubowski A, Kolodziej M, et al. Comparison of endobronchial ultrasound and/or endoesophageal ultrasound with transcervical extended mediastinal lymphadenectomy for staging and restaging of non-small-cell lung cancer. J Thorac Oncol 2013; 8: 630-636.

60 Herth FJ, Annema JT, Eberhardt R, et al. Endobronchial ultrasound with transbronchial needle aspiration for restaging the mediastinum in lung cancer. J Clin Oncol 2008; 26: 3346-3350.

61 Szlubowski A, Herth FJ, Soja J, et al. Endobronchial ultrasound-guided needle aspiration in non-small-cell lung cancer restaging verified by the transcervical bilateral extended mediastinal lymphadenectomy - a prospective study. Eur J Cardiothorac Surg 2010; 37: 1180-1184.

62 Szlubowski A, Zielinski M, Soja J, et al. Accurate and safe mediastinal restaging by combined endobronchial and endoscopic ultrasound-guided needle aspiration performed by single ultrasound bronchoscope. Eur $J$ Cardiothorac Surg 2014; 46: 262-266.

63 Vazquez-Sequeiros E, Levy MJ, Van Domselaar M, et al. Diagnostic yield and safety of endoscopic ultrasound guided fine needle aspiration of central mediastinal lung masses. Diagn Ther Endosc 2013; 2013: 150492.

64 Annema JT, Veseliç M, Rabe KF. EUS-guided FNA of centrally located lung tumours following a non-diagnostic bronchoscopy. Lung Cancer 2005; 48: 357-361.

65 Tournoy KG, Rintoul RC, van Meerbeeck JP, et al. EBUS-TBNA for the diagnosis of central parenchymal lung lesions not visible at routine bronchoscopy. Lung Cancer 2009; 63: 45-49.

66 Abrams HL, Spiro R, Goldstein N. Metastases in carcinoma; analysis of 1000 autopsied cases. Cancer 1950; 3: 74-85.

67 Stone WZ, Wymer DC, Canales BK. Fluorodeoxyglucose-positron-emission tomography/computed tomography imaging for adrenal masses in patients with lung cancer: review and diagnostic algorithm. $J$ Endourol 2014; 28: 104-111.

68 Pieterman RM, van Putten JW, Meuzelaar JJ, et al. Preoperative staging of non-small-cell lung cancer with positron-emission tomography. $N$ Engl J Med 2000; 343: 254-261.

69 Osman Y, El-Mekresh M, Gomha AM, et al. Percutaneous adrenal biopsy for indeterminate adrenal lesion: complications and diagnostic accuracy. Urol Int 2010; 84: 315-318.

70 Mody MK, Kazerooni EA, Korobkin M. Percutaneous CT-guided biopsy of adrenal masses: immediate and delayed complications. J Comput Assist Tomogr 1995; 19: 434-439.

71 Chang KJ, Erickson RA, Nguyen P. Endoscopic ultrasound (EUS) and EUS-guided fine-needle aspiration of the left adrenal gland. Gastrointest Endosc 1996; 44: 568-572.

72 Eloubeidi MA, Seewald S, Tamhane A, et al. EUS-guided FNA of the left adrenal gland in patients with thoracic or GI malignancies. Gastrointest Endosc 2004; 59: 627-633.

73 Ang TL, Chua TS, Fock KM, et al. EUS-FNA of the left adrenal gland is safe and useful. Ann Acad Med Singapore 2007; 36: 954-957.

74 Bodtger U, Vilmann P, Clementsen P, et al. Clinical impact of endoscopic ultrasound-fine needle aspiration of left adrenal masses in established or suspected lung cancer. J Thorac Oncol 2009; 4: 1485-1489.

75 Schuurbiers OC, Tournoy KG, Schoppers HJ, et al. EUS-FNA for the detection of left adrenal metastasis in patients with lung cancer. Lung Cancer 2011; 73: 310-315.

76 Eloubeidi MA, Black KR, Tamhane A, et al. A large single-center experience of EUS-guided FNA of the left and right adrenal glands: diagnostic utility and impact on patient management. Gastrointest Endosc 2010; 71: 745-753.

77 Buxbaum JL, Eloubeidi MA. Transgastric endoscopic ultrasound (EUS) guided fine needle aspiration (FNA) in patients with esophageal narrowing using the ultrasonic bronchovideoscope. Dis Esophagus 2011; 24: 458-461.

78 Eloubeidi MA, Morgan DE, Cerfolio RJ, et al. Transduodenal EUS-guided FNA of the right adrenal gland. Gastrointest Endosc 2008; 67: 522-527.

79 Uemura S, Yasuda I, Kato T, et al. Preoperative routine evaluation of bilateral adrenal glands by endoscopic ultrasound and fine-needle aspiration in patients with potentially resectable lung cancer. Endoscopy 2013; 45: 195-201.

80 Haseganu LE, Diehl DL. Left adrenal gland hemorrhage as a complication of EUS-FNA. Gastrointest Endosc 2009; 69: e51-e52.

81 Steinfort DP, Hew MJ, Irving LB. Bronchoscopic evaluation of the mediastinum using endobronchial ultrasound - a description of the first 216 cases performed at an Australian tertiary hospital. Intern Med J 2011; 41: 815-824.

82 Stather DR, Maceachern P, Chee A, et al. Trainee impact on advanced diagnostic bronchoscopy: an analysis of 607 consecutive procedures in an interventional pulmonary practice. Respirology 2013; 18: 179-184. 

Med 2007; 176: 99.

84 Cook DA, Hatala R, Brydges R, et al. Technology-enhanced simulation for health professions education: a systematic review and meta-analysis. JAMA 2011; 306: 978-988.

85 Konge L, Annema J, Clementsen P, et al. Using virtual-reality simulation to assess performance in endobronchial ultrasound. Respiration 2013; 86: 59-65.

86 Stather DR, Maceachern P, Rimmer K, et al. Validation of an endobronchial ultrasound simulator: differentiating operator skill level. Respiration 2011; 81: 325-332.

87 Stather DR, Maceachern P, Chee A, et al. Wet laboratory versus computer simulation for learning endobronchial ultrasound: a randomized trial. Can Respir J 2012; 19: 325-330.

88 Polkowski M, Larghi A, Weynand B, et al. Learning, techniques, and complications of endoscopic ultrasound (EUS)-guided sampling in gastroenterology: European Society of Gastrointestinal Endoscopy (ESGE) Technical Guideline. Endoscopy 2012; 44: 190-206.

89 Folch E, Majid A. Point: are $>50$ supervised procedures required to develop competency in performing endobronchial ultrasound-guided transbronchial needle aspiration for mediastinal staging? Yes. Chest 2013; 143: 888-891.

90 Eisen GM, Dominitz JA, Faigel DO, et al. Guidelines for credentialing and granting privileges for endoscopic ultrasound. Gastrointest Endosc 2001; 54: 811-814.

91 Wani S, Cote GA, Keswani R, et al. Learning curves for EUS by using cumulative sum analysis: implications for American Society for Gastrointestinal Endoscopy recommendations for training. Gastrointest Endosc 2013; 77: $558-565$.

92 Vilmann P, Saftoiu A. Endoscopic ultrasound-guided fine needle aspiration biopsy: equipment and technique. J Gastroenterol Hepatol 2006; 21: 1646-1655.

93 Annema JT, Bohoslavsky R, Burgers S, et al. Implementation of endoscopic ultrasound for lung cancer staging. Gastrointest Endosc 2010; 71: 64-70.

94 Konge L, Annema J, Vilmann P, et al. Transesophageal ultrasonography for lung cancer staging: learning curves of pulmonologists. J Thorac Oncol 2013; 8: 1402-1408.

95 Bolliger CT, Mathur PN, Beamis JF, et al. ERS/ATS statement on interventional pulmonology. European Respiratory Society/American Thoracic Society. Eur Respir J 2002; 19: 356-373.

96 Ernst A, Silvestri GA, Johnstone D. Interventional pulmonary procedures: guidelines from the American College of Chest Physicians. Chest 2003; 123: 1693-1717.

97 Kinsey CM, Channick CL. Counterpoint: are $>50$ supervised procedures required to develop competency in performing endobronchial ultrasound-guided transbronchial needle aspiration for lung cancer staging? No. Chest 2013; 143: 891-893.

98 Du Rand IA, Barber PV, Goldring J, et al. Summary of the British Thoracic Society guidelines for advanced diagnostic and therapeutic flexible bronchoscopy in adults. Thorax 2011; 66: 1014-1015.

99 Konge L, Vilmann P, Clementsen P, et al. Reliable and valid assessment of competence in endoscopic ultrasonography and fine-needle aspiration for mediastinal staging of non-small cell lung cancer. Endoscopy 2012; 44: 928-933.

100 Davoudi M, Colt HG, Osann KE, et al. Endobronchial ultrasound skills and tasks assessment tool: assessing the validity evidence for a test of endobronchial ultrasound-guided transbronchial needle aspiration operator skill. Am J Respir Crit Care Med 2012; 186: 773-779. 